\title{
Transparency
}

\author{
Benjamin Worthy
}

Christopher Hood and David Heald define transparency as a glass-like process allowing those outside to look in, a metaphoric and literal 'peering through the window' illustrated by the glass of the German Reichstag (Heald, 2006; Hood and Heald, 2006). The concept is synonymous with openness and is rooted in the idea of letting in light or knowledge (Bok, 1986). Transparency over the last decade has been entrenched within political discourse as a kind of universal good that is both an instrumental means to a number of positive outcomes (such as improved trust or accountability) and an end in itself (Meijer, 2013). It is, moreover, an idea that is universally supported across the political spectrum as a means of opening up institutions to public scrutiny (Birchall, 2014).

Underneath this acceptance, transparency can entail many things. Darch and Underwood describe it as an ideologically-determined political initiative that can be deployed to achieve a range of different agendas' (2010: 4). As these chapters show, the exact dynamics and divisions of the use of the term vary from country to country and area to area. Transparency resembles democracy itself, in that there is a general consensus on the concept but its interpretation is 'open to complexity, contradiction and numerous varieties': it is in some senses an empty signifier that can be filled by very different interpretations or emphases (Stubbs and Snell, 2014: 160). It can have numerous different aims and purposes, from monitoring by the public to hierarchical control of lesser bodies (Heald, 2012). Below are just three examples of what transparency can mean: 
- Political empowerment: it is a highly politicised instrument of empowerment, embodying different democratic norms and values (Fenster, 2012a).

- Policy solution: it can be a 'dramatically satisfying answer to every crisis and question about the state' (Fenster, 2015).

- Economic improvement: it is a means of increasing efficiency and even wealth, connected to a 'consumer-citizen' idea of delivery and performance measurement.

On a symbolic level, transparency policy can then be used as a radical weapon of empowerment, a tool of modernisation and a means of demonstrating an institution or organisation is more ethical, more honest or more trustworthy. Such a policy can 'allow an incumbent to make credible promises of greater transparency and anti-corruption efforts to a wary public' (Berliner, 2014: 479). It also represents an 'apparently simple solution to complex problems - such as how to fight corruption, promote trust in government, support corporate social responsibility, and foster state accountability' and is an acceptable response to problems 'at moments of crisis or moral failure', a 'visible response to public disquiet [with] attractive, palliative qualities for politicians and CEOs who want to be seen to be doing rather than reflecting' (Birchall, 2014: 77).

However, beneath the symbolism of any openness policy its dominant message is fundamentally contested. Questions asking what sort of transparency is created, of whom and by whom, expose the complex politics underlying its use (Berliner, 2014). As the famous freedomof-information (FOI) campaigner Tom Blanton said, the goal to initiate transparency is 'not a sudden conversion' but one created by the 'specific conditions of competition for political power' (quoted in Darch and Underwood, 2010: 64). There is a constant, highly politicised struggle to define what a policy of openness can and should do (Fenster, 2015; Yu and Robinson, 2012). Classic arguments for transparency are rooted in both rational choice theories of behaviour change and principled ideas of the moral rightness of openness (Birchall, 2014; Chambers, 2004; Darch and Underwood, 2010). For governments it is often imbued with a very particular, often neo-liberal, conception of state-society relations. More radical conceptions see it as a weapon that can be used against these same neo-liberal ideas and reverse the assumptions 
of who is being open to whom, and debate the size of the political spaces opened (or closed) by its arrival (Birchall, 2014). Julian Assange and Theresa May are both vocal supporters of transparency, but they are unlikely to agree on what it means and who it should affect. Transparency remains a 'contested political issue that masquerades as an administrative tool' (Fenster, 2012b: 449).

Transparency is in sharp contrast with the idea of secrecy. The dangers of secrecy to becoming enlightened, and the opening up of forbidden matters resonate across mythology, from Pandora's box to the story of Faust. Modern bureaucratic secrecy grew from the mysterious aura that surrounded the divine right of kings in the seventeenth century (Bok, 1986). This secrecy was justified by the demands of security or to protect sensitive decisions, and bound up in an aura designed to elicit awe and often buried in a 'rich array of ritualistic and symbolic practices' (Costas and Grey, 2014: 1425-1426). Secrecy can be secured in the shape of formal institutional rules and regulations (such as official secrecy legislation or gagging clauses), or it can be obtained informally through unofficial concealment, taboos and socialisation (such as codes of silence, or agreed and shared needs for secrecy).

The clash between openness and secrecy equates, rather too simply, to that between good and bad, and democratic and undemocratic. There has been a growing view in democracies across the world that secrecy, or too much concealment, is 'incompatible with democracy', and it continues to be associated with evil, with 'stealth and furtiveness, lying and denial' (Bok, 1986: 8). This characterisation oversimplifies a more nuanced reality, as secrecy is closely entwined with a more positive notion of privacy, while publicity can be associated with manipulation and distortion (Bok, 1986). There are also broad swathes of social and political activity where confidentiality is accepted and deemed necessary, from the work of juries to peace negotiations, and even staunch advocate of openness and transparency Jeremy Bentham qualified the power of publicity with the need to prevent injustice (Chambers, 2004).

A further difficulty is that transparency is many things at once. It is achieved through laws but also by technology and experiments. It is partly about making politicians and institutions accountable for what they do - sometimes over minor matters and sometimes over 
big ones. Yet it can be, and often is, a practical tool to help people in their everyday lives. For all the attention given to scandals such as MPs' expenses, FOI legislation and access to online data are most often used to help individuals and for local or 'micro-political' issues (Worthy and Hazell, 2017).

\section{Transparency and institutions}

Transparency regulations have been slowly applied across many institutions in the past two decades, from government to central banks and from local to supranational bodies. To take the example of the UK, the Freedom of Information Act 2000, which is possibly the centrepiece of Britain's transparency regime, operates in more than 100,000 public bodies from central and local government to the police, hospitals, libraries and schools. Alongside this, specific sector-based laws have allowed people to access certain data about a range of areas from medical records to estate agents' fees, while open-data policies straddle many policy areas. Transparency regulations have also spread to the private sector, from procurement openness clauses in contracts, to publishing data on ownership of companies and multinational tax reporting.

Thus, the boundaries surrounding transparency are constantly moving. Disclosures using formal routes sit alongside leaks, semiauthorised disclosures and plants, innovations, and radical actions like WikiLeaks or the Panama papers that can all kick-start transparency and gradually shift the border between open and closed or legal and illegal disclosures (Pozen, 2013). There is rarely a clear distinction between how transparency is produced. For example, is it through an appeal to FOI laws, a leak or whistleblowing? As a consequence, the legitimacy of disclosure falls along a continuum, with government press releases at one end and Edward Snowden at the other. It is most often the government that delineates what it sees as the legal boundaries of openness; for example, of FOI laws or secrecy legislation. Government frames the narrative over where transparency begins and ends. The exact effect of transparency varies from institution to institution. Local government has long held open meetings and has probably dealt more successfully with demands for transparency than central government. Parliament has struggled with scandal but has altered its culture towards 
being more open (Worthy and Hazell, 2017). The overt assumption behind these changes is that transparency will trigger a chain of reactions across institutional domains:

- The public will be interested and use the information and data that are published.

- The public and others will act upon the data to leverage change across organisations.

- Transparency will trigger cultural and behavioural change within institutions.

Research increasingly questions and modifies each of these assumptions. There is no general ideal user of information and, while some openness initiatives generate public interest, others do not. FOI laws in the UK are well used, but the numerous open-data experiments have proved far more variable. As Roberts (2015) points out, the chain of events from asking for or accessing data to actually receiving them and levering change is long and weak. If or whether it can lever reforms depends on the context in which the information is placed and whether the instruments are available to enforce institutional or behavioural change as a result (de Fine Licht, 2014). The hope lying behind transparency that such information will influence or persuade rational, calculating voters or engaged citizens has not been borne out (Bauhr and Grimes, 2014). Users and voters hold 'deeply engrained' views about government and other institutions that are hard to dislodge. Any change coming about as a result of new information appears to be brief and subject specific (Marvel, 2016).

As to whether transparency drives cultural change, it can and has opened up diverse institutions from local government to parliament. How exactly an agent or body reacts to pressure for transparency can vary, from enthusiastic experimentation to minimal compliance and occasional outright resistance (Prat, 2006). Transparency reforms can transform a body or can be diluted, getting lost amid institutional wrangling or grinding to a halt against institutional resistance to change, as seen in the EU (Hillebrandt et al., 2014). While the evidence is slight for any perverse chilling effect, some politicians undoubtedly see transparency as a burden and symbolic of a constrained government, and have built a powerful counter-discourse around its (largely unsubstantiated) negative effects. 


\section{Transparency and the public}

In the chapters in this part we can see that transparency policies can be a powerful tool for opening up bodies as they give citizens the 'capacity to penetrate ... defences and strategies' built up over centuries to preserve secrecy, and offer them the chance to create what Jeremy Bentham called a 'system of distrust' to monitor their rulers or those acting in their name (Bok, 1986: 9).

Generally, only a very small percentage of the population ever use the tools of transparency (Worthy and Hazell, 2017). There are a number of ways by which the public learns about transparency issues. First, they often appear in the media and political discourse as solutions to crises. Scandals, exposés or shocks, ranging from political corruption to financial crashes, create a demand for greater openness. Alternatively, the lack of openness is seen as the cause of the crisis (Roberts, 2012). Secondly, as Fenster (2015) points out, transparency has also 'captured the popular imagination' in narratives about whistleblowing or heroic leaks, such as the leaks on the 2009 MPs' expenses or those by Snowden in 2013. The existence of mechanisms such as FOI laws provide daily reminders in the media of the role and value of openness.

As all the chapters in this part mention, public interest in and use of the new transparency opportunities vary from case to case. There is a broad public awareness in the UK that some formal means of transparency exist, such as the FOI laws, and there is a general (if vague) support for them. In terms of leaks and 'radical transparency' such as Snowden's leaks and WikiLeaks, public opinion is unclear and shifts between different contexts. While there is a powerful supportive folklore on whistleblowing, expectations and concerns over national security can divide opinion as to the ethics and effects of these actions (Fenster, 2012a; Roberts, 2012). Some fascinating experiments indicate that the public support and are reassured by the presence of transparency mechanisms but have little desire to use them, instead preferring to rely on other citizens to operate them and unleash their benefits (see de Fine Licht, 2014; de Fine Licht et al., 2014).

Research shows that there are numerous disconnects over public opinion and transparency, and various factors that can shape its impact:

- Context is key. Although transparency is seen as a good thing, the battle over what it means and what its limits should be 
undoubtedly raises a series of competing and contradictory issues. Transparency overlaps with the ethics of leaks, privacy and national security. The view held by the public of any kind of transparency at any one time is highly context dependent. A leaker of classified information like Snowden may be viewed very differently than the anonymous leaker of MPs' expenses.

- Flawed assumptions. The idea underlying transparency - namely, that information empowers rational, calculating citizens - is misplaced, though politicians continue to press it. All those who receive information have biases, and employ heuristic assumptions that shape their ideas and views. These views may interrupt the flow or change the meaning of information disclosed. All transparency systems and instruments are shaped by the environment and political context in which they are created (Meijer, 2013).

- Competing visions and meanings. The debate over transparency and its effects continues, but may further complicate discussion rather than resolve it as different sides pull against each other. Governments seek a depoliticised (or redirected) transparency focused on efficiency or improving services, while activists seek greater openness of different parts of the state (and, increasingly, the private sector). The different language used and different aims may push discussion in divergent directions.

- Fluid borders. The exact boundaries of transparency are constantly moving. Disclosures through leaks, semi-authorised disclosures and plants, innovations such as open data, and 'radical' actions like Wikileaks can all provide an impetus to transparency and gradually move the border between 'open' and 'closed' or 'legal' and 'illegal' (Pozen, 2013). Meaning is greatly complicated by the closing off of certain issues, not least the transparency of citizens through government surveillance, a rarely mentioned aspect of the wider transparency debate (Birchall, 2014).

\section{The chapters}

The three chapters in this part discuss these themes in different areas, looking at the opportunities and pitfalls that transparency presents 
across three very different institutions and systems. They show it is far from simple to understand transparency.

Stephen Curry examines the potential of open access to academic research to break down barriers and open up research and knowledge to the wider public. There have been notable steps forward from funders and also from individual online innovators. However, acceptance of the idea across academia has been patchy. So far, there is evidence of some progress but there are economic and cultural barriers to the need to publish, in some cases triggered by outright resistance to the principle of engaging more widely, as seen in the case of NASA. Demand for greater access on the part of citizen users is just as uneven. Nevertheless, the momentum provided by funders and technology means open access is here to stay.

Carmen McLeod examines one of the most sensitive connections between openness and privacy in the transparency of animal testing. This chapter maps two rather different approaches, in the UK and Switzerland, and argues that information supplied about animal experiments will not be enough to mend the historically troubled relations between animal-research science and society. On the one hand, it is argued that the public have a clear right to know about what is done in their name and, on the other, there is held to be a right to privacy and a need for protection. The case illustrates how the demands of transparency must be balanced with other competing and compelling needs and rights. At its borders, transparency interacts in complex ways with other sensitive rights including privacy, confidentiality and security.

The final chapter by Roda Madziva and Vivien Lowndes on Christian asylum seekers and the UK Border Agency (UKBA) challenges some of the assumptions about openness and the idea that clear, neutral information is the bedrock of transparency. Information is profoundly shaped by its sociopolitical context and the hidden and not-so-hidden biases or ignorance that shape our environment. Their qualitative research shows how vital basic data may be misconstrued and misunderstood, and also placed within particular institutional narratives that not only close off the fairness that such procedures bring but even create perverse outcomes.

Increased openness is frequently offered by governments or organisations as a symbol of their difference from their predecessors 
or competitors, or their commitment to certain values and ways of working. Yet these chapters show that while transparency can change institutions, institutions can also remake transparency in their own image.

\section{References}

Bauhr, M., and Grimes, M. (2014). Indignation or resignation: The implications of transparency for societal accountability. Governance, 27(2), 291-320.

Berliner, D. (2014). The political origins of transparency. Journal of Politics, 76(2), 479-491.

Birchall, C. (2014). Radical transparency? Cultural Studies $\leftrightarrow$ Critical Methodologies, 14(1), 77-88.

Bok, S. (1986). Secrets: Concealment and Revelation. Oxford: Oxford University Press.

Chambers, S. (2004). Behind closed doors: Publicity, secrecy, and the quality of deliberation. Journal of Political Philosophy, 12(4), 389-410.

Costas, J., and Grey, C. (2014). Bringing secrecy into the open: Towards a theorization of the social processes of organizational secrecy. Organization Studies, 35(10), 1423-1447.

Darch, C., and Underwood, P. G. (2010). Freedom of Information and the Developing World: The Citizen, the State and Models of Openness. Oxford, Cambridge, New Delhi: Chandos.

de Fine Licht, J. (2014). Policy area as a potential moderator of transparency effects: An experiment. Public Administration Review, 74(3), 361-371.

de Fine Licht, J., Naurin, D., Esaiasson, P., and Gilljam, M. (2014). When does transparency generate legitimacy? Experimenting on a context-bound relationship. Governance, 27(1), 111-134.

Fenster, M. (2012a). Disclosure's effects: WikiLeaks and transparency. Iowa Law Review, 97, 753-780.

Fenster, M. (2012b). The transparency fix: Advocating legal rights and their alternatives in the pursuit of a visible state. University of Pittsburgh Law Review, 73(3), 443-503. Retrieved 15 December 2015 from: http://ssrn.com/ abstract $=1918154$.

Fenster, M. (2015). Transparency in search of a theory. European Journal of Social Theory, 18(2), 150-167.

Heald, D. (2006). Transparency as an instrumental value. In C. Hood and D. Heald (eds), Transparency: The Key to Better Governance? (pp. 59-73). Oxford: Oxford University Press for The British Academy.

Heald, D. (2012). Why is transparency about public expenditure so elusive? International Review of Administrative Sciences, 78(1), 30-49. 
Hillebrandt, M. Z., Curtin, D., and Meijer, A. (2014). Transparency in the EU Council of Ministers: An institutional analysis. European Law Journal, 20(1), 1-20.

Hood, C., and Heald, D. (eds) (2006). Transparency: The Key to Better Governance? Oxford: Oxford University Press for the British Academy.

Marvel, J. D. (2016). Unconscious bias in citizens' evaluations of public sector performance. Journal of Public Administration Research and Theory, 26(1), 143-158.

Meijer, A. (2013). Understanding the complex dynamics of transparency. Public Administration Review, 73(3), 429-439.

Pozen, D. (2013). The leaky Leviathan: Why the Government condemns and condones unlawful disclosures of information. Harvard Law Review, 127, 512-635.

Pratt, A. (2006). The more closely we are watched, the better we behave? In C. Hood and D. Heald (eds), Transparency: The Key to Better Governance? (pp. 91-103). Oxford: Oxford University Press for the British Academy.

Roberts, A. S. (2012). Transparency in troubled times. Tenth World Conference of the International Ombudsman Institute, November 2012, Suffolk University Law School Research Paper 12-35. Retrieved 14 July 2016 from: https:// ssrn.com/abstract $=2153986$.

Roberts, A. S. (2015). Promoting fiscal openness. GIFT: Global Initiative for Fiscal Transparency. Retrieved 6 July 2016 from: www:fiscaltransparency.net/ wp-content/themes/enfold/includes/gift_embedded/en/resource_open.php ?IdToOpen=20150704111.

Stubbs, R., and Snell, R. (2014). Pluralism in FOI law reform: Comparative analysis of China, Mexico and India. University of Tasmania Law Review, 33(1), 141-164.

Worthy, B., and Hazell, R. (2017). Disruptive, dynamic and democratic? Ten years of FOI in the UK. Parliamentary Affairs, 70(1), 22-42.

Yu, H., and Robinson, D. G. (2012). The new ambiguity of 'open government'. UCLA Law Review Discourse, 59, 178-208. Retrieved 12 January 2016 from: http://ssrn.com/abstract=201248. 